\title{
Influence of foreign object damage on fatigue crack growth of gas turbine aerofoils under complex loading conditions
}

\author{
R. HALL, J. BYRNE, T. ZHAO and J. TONG \\ Department of Mechanical and Design Engineering, University of Portsmouth, Anglesea Building, Anglesea Road, Portsmouth PO1 3DF, UK \\ Received in final form 16 April 2008
}

A B S TRACT Foreign object damage (FOD) has been identified as one of the main life limiting factors for aeroengine blades, with the leading edge of aerofoils particularly susceptible. In this work, a generic edge 'aerofoil' geometry was utilized in a study of early fatigue crack growth behaviour due to FOD under low cycle fatigue (LCF), high cycle fatigue (HCF) and combined LCF and HCF loading conditions. Residual stresses due to FOD were analyzed using the finite element method. The longitudinal residual stress component along the crack path was introduced as a nodal temperature distribution, and used in the correction of the stress intensity factor range. The crack growth was monitored using a nanodirect current potential drop (DCPD) system and crack growth rates were correlated with the corrected stress intensity factor considering the residual stresses. The results were discussed with regard to the role of residual stresses in the characterization of fatigue crack growth.

Small crack growth behaviour in FODed specimens was revealed only after the residual stresses were taken into account in the calculation of the stress intensity factor, a feature common to LCF, HCF and combined LCF + HCF loading conditions.

Keywords aerofoil; combined loading: fatigue crack growth; FOD; residual stress

\section{INTRODUCTION}

Foreign object damage (FOD) has been identified as one of the main life limiting factors for aeroengine blades, ${ }^{1,2}$ with the leading edge of aerofoils particularly susceptible. Impacts due to small hard particle ingestion during takeoff and landing can reach velocities in the range of 60 to $500 \mathrm{~m} / \mathrm{s}$ and cause severe damage to aerofoils. Damage due to FOD is estimated at $\$ 4$ billion annually for the aeroengine industry. ${ }^{1}$ The effects of FOD on high cycle fatigue (HCF) have been studied extensively for Ti-6Al$4 \mathrm{~V}$ blade alloy, largely as a result of the National High Cycle Fatigue Program in the United States, by Ritchie and his associates, ${ }^{3-9}$ Nicholas et al., ${ }^{10-12}$ and in the UK at Swansea, ${ }^{13,14}$ Oxford ${ }^{15,16,17}$ and Portsmouth. ${ }^{18,19}$ The residual stress state due to spherical hard body impact has been characterized. ${ }^{6-9}$ Similarly, the effects of impact by cubical projectile have been studied by Nowell et al. on the reduction in fatigue strength; ${ }^{15,16}$ and by Ding et al. on early crack growth in plate specimens. ${ }^{18,19}$ The mechanistic effect of FOD on fatigue behaviour may be considered

Correspondence: J. Tong. E-mail: jie.tong@port.ac.uk in terms of (i) stress concentration associated with the shape of the impact crater; (ii) micro-structural damage, with or without micro-cracking, due to FOD and (iii) stabilised residual stresses in the vicinity of the impact site. Most studies have focused on determining the onset condition below which fatigue failure due to FOD will not occur, considering (i) explicitly. A Kitagawa-Takahashi approach has been used, where the limiting conditions are defined by a stress concentration corrected smoothbar fatigue limit (for small cracks) and a 'worst-case' fatigue crack growth threshold (for long cracks). A modification of this approach by El Haddad et al. ${ }^{20}$ has been employed $^{5,16}$ to redefine the failure envelopes such that small crack behaviour can be accommodated. Such an approach, however, is insufficient when a flight cycle is concerned, where the threshold for a combined HCF and low cycle fatigue (LCF) is lower, ${ }^{21}$ as the flight cycle serves as an underload to the HCF cycles at high $\mathrm{R}$ ratio, such that the threshold condition determined by standard tests for HCF cannot be applied to combined loading cases. In such components, the LCF, or major cycle loading, arises from the large cyclic variation of the conjoint centrifugal and thermal stresses, normally occurring once per flight, 
while the HCF or minor cycle loading arises from smallamplitude vibrations. During flight these high-frequency minor cycles are usually superimposed on each major cycle, such that the fatigue integrity assessment must consider the effect of combined HCF and LCF loadings on crack growth. ${ }^{22,23}$

A recent study by the present authors ${ }^{18,19}$ examined the influence of FOD on early crack growth behaviour in rectangular plate specimens of Ti-6Al-4V alloy, where a combined LCF/HCF loading block, including a single LCF cycle and 1000 HCF cycles, was applied post-FOD. The crack growth behaviour of these FOD-initiated small cracks under combined LCF/HCF loading was found to differ significantly from that of large cracks obtained on corner cracked specimens, and to differ also from those under LCF- or HCF-only cycles. Although the work provided valuable information on fatigue crack growth due to FOD under combined LCF and HCF loading conditions, the geometry of the plate specimens differs considerably from that of blades. In this work, a generic edge 'aerofoil' geometry, representative of fan blades and guide vanes, was utilized in a study of early fatigue crack growth behaviour due to FOD under LCF, HCF and combined LCF and HCF loading conditions. Residual stresses due to FOD were analyzed using the finite element method, and the longitudinal residual stress component along the crack path was introduced as a nodal temperature distribution, and used in the correction of the stress intensity factor range. The crack growth was monitored using a nanovoltmeter based direct current potential drop (DCPD) system and crack growth rates were correlated with the stress intensity factors for an aerofoil specimen, a standard single edge crack solution and a corrected stress intensity factor considering the residual stresses. The results are discussed with regard to the role of residual stresses in the characterization of fatigue crack growth.

\section{EXPERIMENTAL STUDIES}

\section{Materials and specimen}

The material used for this study is titanium alloy $\mathrm{Ti}$ $6 \mathrm{Al}-4 \mathrm{~V}$, a well-established alpha-beta general purpose alloy with a typical micro-structure of a bimodal distribution of primary $\alpha$ phase and lamellar colonies of $\alpha+\beta$. The material was forged and then rolled into plate form, from which the specimens were made. Typical materials properties at room temperature are: Young's modulus, $103 \mathrm{GPa}$, yield stress, $860 \mathrm{MPa}$ and tensile strength, 980 $\mathrm{MPa}{ }^{18}$ Although crack propagation data have been obtained using plate ${ }^{18}$ and corner notched ${ }^{22,23}$ specimens, FOD damage on blades in aero-engines is known to occur on the leading edge of an aerofoil section. Thus, a specimen geometry was developed incorporating a simplified aerofoil section over the gauge length with a cross-section area similar to that of corner notched specimens, as shown in Fig. 1.

To impart FOD to the specimen, a $3 \mathrm{~mm}$ hardened steel cube was fired onto the leading edge of the specimen at a velocity of $\sim 200 \mathrm{~m} / \mathrm{s}$ using a light gas gun at QinetiQ. The trajectory of the cube was perpendicular to the longitudinal axis of the specimen, and the impact was 'nose-on' the leading edge. To study the effect of residual stresses on the development of cracks in the specimens, baseline tests were carried out on specimens that had been stressrelieved after FOD. The latter were obtained by heating the specimens to $700{ }^{\circ} \mathrm{C}$ for $2 \mathrm{~h}$ in vacuum before mechanical testing.

\section{Characterization of foreign object damage}

A scanning electron micrograph (SEM) of a FOD indent in an untested aerofoil specimen is presented in Fig. 2a, showing the FOD damage on the leading edge of the aerofoil specimen. Extensive plastic deformation is evident from the severe distortion of the machining marks on the surface above and below the indent. No obvious micro-cracking was found though. The specimen used for the SEM investigation was subsequently installed in a plastic mount and ground back enabling the cross section of the indent to be observed. The specimen was then sectioned parallel to the long axis of the specimen, polished and etched using Kroll's Reagent $(2 \mathrm{~mL} \mathrm{HF}+4 \mathrm{~mL}$ $\mathrm{HNO}_{3}+100 \mathrm{~mL} \mathrm{H}_{2} \mathrm{O}$ ) to reveal the severely deformed micro-structure, as shown in Fig. 2b. The depths of the indent due to FOD were found to be $0.75 \pm 0.12 \mathrm{~mm}$.

\section{Crack monitoring and measurement}

As there was no previous experience of testing aerofoil specimens, several experiments were carried out to establish and evaluate an effective DCPD method in detecting and monitoring early crack growth, including the appropriate positions for the DCPD probe wires on the specimen. DCPD reference probe wires were welded at one end of the gauge length in the centre of the parallel sections of the specimen. A distance between the probe wires of $0.76 \mathrm{~mm}$ was used, the same as for corner notch specimens $^{23}$ (Fig. 3a). Finding the appropriate positions for active DCPD wires proved to be more difficult, as crack growth occurred from one of the welds on the first attempt. Subsequent stress analysis using the finite element method revealed that the location of the weld coincided with a region of high tensile residual stress post-FOD. By trial and error, the position of the active probe wires was finally decided at $2.5 \mathrm{~mm}$ either side of the centre of the indent to achieve the sensitivity required while avoiding high tensile stress regions (Fig. 3a). 
In our previous work, ${ }^{21,23}$ crack monitoring during testing was carried out using a DCPD system with a millivoltmeter to monitor the changes in the voltage as the crack extends. In the current study, a DCPD system with a nano-voltmeter has been used. The standard deviation of nano-voltage readings is $8 \times 10^{-5}$ volts. The high sensitivity is necessary for the detection and the monitoring of early fatigue crack growth due to FOD. During the experiments, cycling was stopped periodically and two methods were used to detect the early crack growth and to measure the crack extension. Firstly, a twin-pack synthetic rubber replicating compound was applied to the area of the indent that made a faithful detailed $3 \mathrm{D}$ replica of the area covered. After curing, the rubber was peeled off and inspected under a measuring microscope. The second method was by traditional acetate film, in which a piece of film was positioned over the crack, acetone applied to soften it, then peeled off after hardening for microscopic examination. The second method is only effective when a dominant crack can be identified outside of the indent.

A calibration experiment was carried out to establish the relationship between voltage ratio and crack length. The DCPD voltage ratio, the ratio of the active and the reference voltage readings, was recorded during the experiment, while, periodically, the crack length was measured using both acetate and rubber replication. A simple linear relationship between voltage ratio and crack length was assumed and validated by the subsequent experimental results (Fig. 3b).

\section{Experimental procedures}

The experiments were undertaken on a servo-hydraulic twin-actuator $100 \mathrm{kN}$ fatigue testing machine designed for HCF + LCF load applications. One actuator is located in the bed of the machine and is designed to apply the LCF component, while the second actuator is located on the crosshead of the machine and is designed to apply the HCF component at a frequency up to $100 \mathrm{~Hz}$. Each actuator was independently controlled by a computer to which data for potential drop readings as well as the other loading parameters were also stored.

Experiments were carried out under LCF at load ratio of $0.1, \mathrm{HCF}$ at load ratio of 0.7 and a block loading of combined LCF and HCF cycles representing a simplified flight spectrum with 1 LCF cycle superimposed by 1000 HCF cycles, all at room temperature. A schematic of a combined loading block is shown in Fig. 4. The maximum stress in all tests was $360 \mathrm{MPa}$, in line with tests on FOD plate specimens previously reported. ${ }^{18}$ LCF-only cycles had a trapezoidal waveform with 1 second rise and fall, and dwell at maximum and minimum load with a base frequency of $0.25 \mathrm{~Hz}$. HCF-only cycles had a sinu- soidal waveform at $80 \mathrm{~Hz}$. These waveforms were used for combined LCF + HCF loading blocks where dwell at maximum load was extended to incorporate $1000 \mathrm{HCF}$ cycles. Eight experiments were carried out in total, as summarised in Table 1. Two specimens were stress-relieved post-FOD and used for baseline testing purposes.

\section{Experimental results}

The voltage ratios were recorded as a function of the number of cycles for all experiments and converted into crack length versus number of cycles using the calibration curve (Fig. 3b) and the measured crack length at the beginning and the end of each experiment. Figure 5 shows the crack length (with indent depth included) as a function of number of cycles for LCF (a), HCF (b) and combined LCF and HCF (c) loading conditions. A consequence of variation in indent depth is that different values of crack length were recorded at the beginning of each experiment.

For LCF-only cycles (Fig. 5a), the effect of FOD impact on delaying crack growth is apparent as the two as-FODed specimens have much longer lives than the stress-relieved specimen, although once the cracks grow, the patterns of crack growth appear to be similar in that fast crack growth towards fracture prevailed. The stress relief heat treatment does not appear to affect the measured crack growth rates, as the crack growth rates from stress-relieved aerofoil specimens compared well with those from cornercracked specimens for LCF, HCF and combined LCF + $\mathrm{HCF}$, despite the apparent difference in the specimen geometries. For HCF-only cycles, there is a large difference in the numbers of cycles experienced before significant crack growth was detected in the two specimens tested. Whilst the crack growth patterns in both tests seem to be comparable to those of LCF tests, the fatigue life of the specimen in test 2 is much longer than the others. For combined LCF + HCF cycles (Fig. 5c), the as-FODed specimens again show a retarded early crack growth rate, as opposed to the stress-relieved specimen. The fatigue lives are shorter due to the conjoint action of LCF and HCF cycles.

Fatigue crack growth rates are correlated, in the first instance, with the stress intensity factor range for a single edge crack in a rectangular cross-section specimen. ${ }^{24}$ From Fig. 6a, the fatigue crack growth rates from the three tests appear to compare reasonably well, once the cracks grow out of the influence of the residual stresses due to FOD. More scattered crack growth rates are observed for FODed specimens during the early stages due to the influence of residual stresses. With combined LCF + HCF cycles (Fig. 6c), there seems to be a close correlation between as-FODed and stress-relieved specimens above a crack length of $\sim 1.8 \mathrm{~mm}(\Delta \mathrm{K} \approx 30 \mathrm{MPa} \sqrt{ } \mathrm{m})$, well clear of the influence of the FOD impact. Data from 
Fig. 1 The aerofoil specimen geometry used in the experiments. All dimensions in $\mathrm{mm}$.
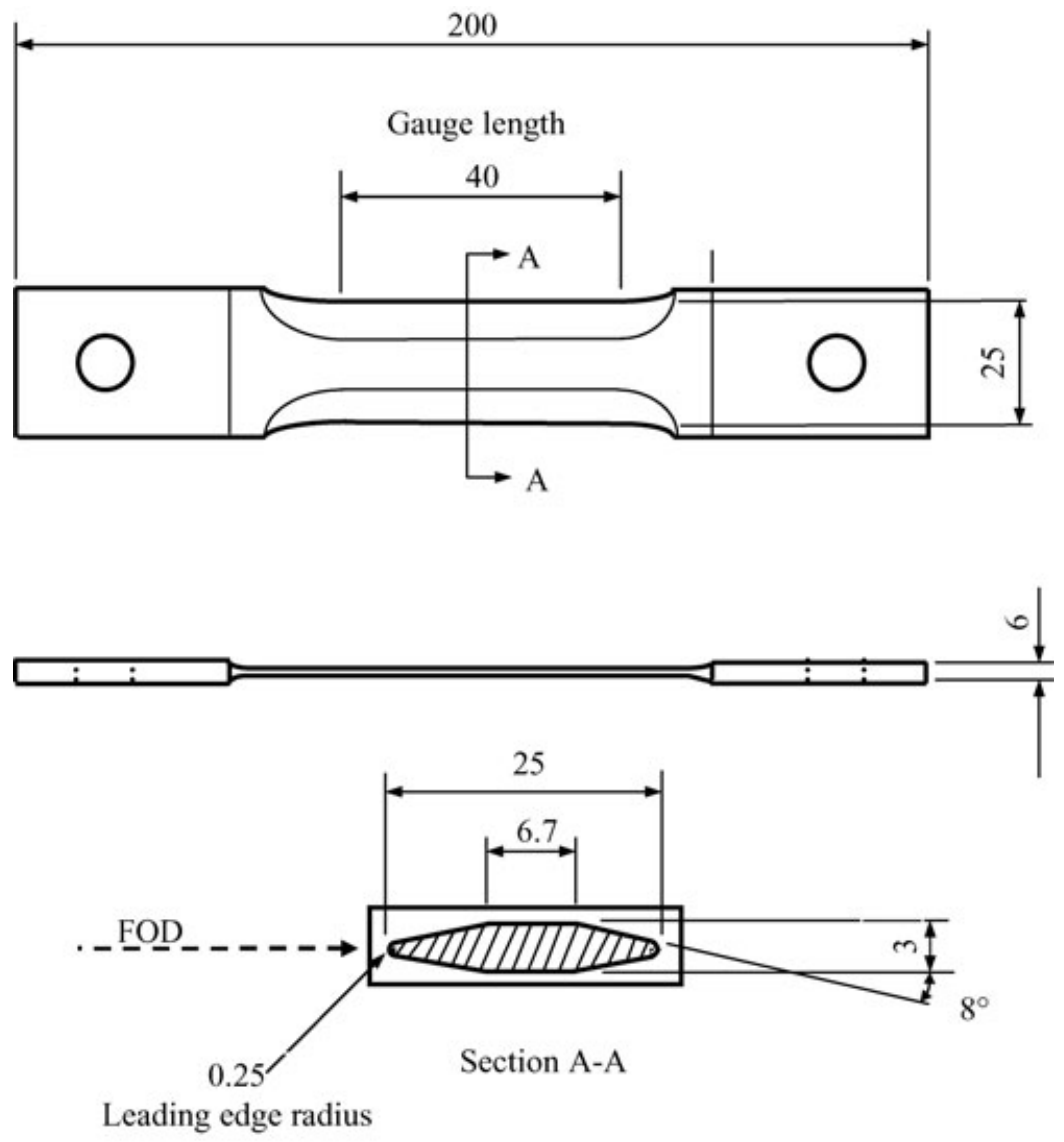

the as-FODed specimens suggests a slow early growth, as in LCF cases, although the crack growth rates are arguably higher in combined loading cases as opposed to LCF or HCF-only loading cases.

\section{FINITE ELEMENT STUDY}

The stress intensity factor in the aerofoil specimen geometry was determined using the finite element method. As the presence of residual stresses due to FOD clearly changes the stress-strain field in the vicinity of the notch tip, particularly in the external loading direction (longitudinal), the stress intensity factor in the presence of a unidirectional residual stress field was determined. The details of the finite element analysis are presented as follows.

\section{The numerical procedures}

FOD damage was simulated using ABAQUS/Explicit ${ }^{25}$ for the time-dependent dynamic analysis. A 3D finite element model of the aerofoil section was developed, as shown in Fig. 7. Only a quarter of the section was modelled due to symmetry. Four-node rigid element R3D4 was used to simulate the cubic projectile, while eight-node linear brick element with reduced integration C3D8R was used for the aerofoil specimen. Refined local mesh was applied to the volume close to the location of the impact. A point-mass element was attached to the projectile to assign the inertia properties. The contact interaction was defined via a contact pair algorithm available in ABAQUS, where the rigid body was chosen as the master contact surface and the surface of the aerofoil specimen against the impacting cube was assigned as the slave contact surface. The basic Coulomb friction model with isotropic friction was employed to invoke friction to prevent slipage of the projectile. The friction coefficient was assumed to be 0.1 , as in. ${ }^{9}$

Alloy Ti-6Al-4V is known to have very low strain hardening, but the material is sensitive to strain rate. To simulate the high-velocity impact, the material model must consider the deformation dependence of strain rate. A power-law model ${ }^{9}$ was chosen for the analysis, where the yield stress was assumed to be a function of strain rate, while strain hardening was neglected. Expressing ratedependent yield stress as a function of strain rate:

$\sigma_{\mathrm{y}}(\dot{\varepsilon})=\left[\left(\frac{\dot{\varepsilon}}{\varepsilon_{\mathrm{r}}}\right)^{\frac{1}{n}}+1\right] \sigma_{\mathrm{y}}^{0}$, 


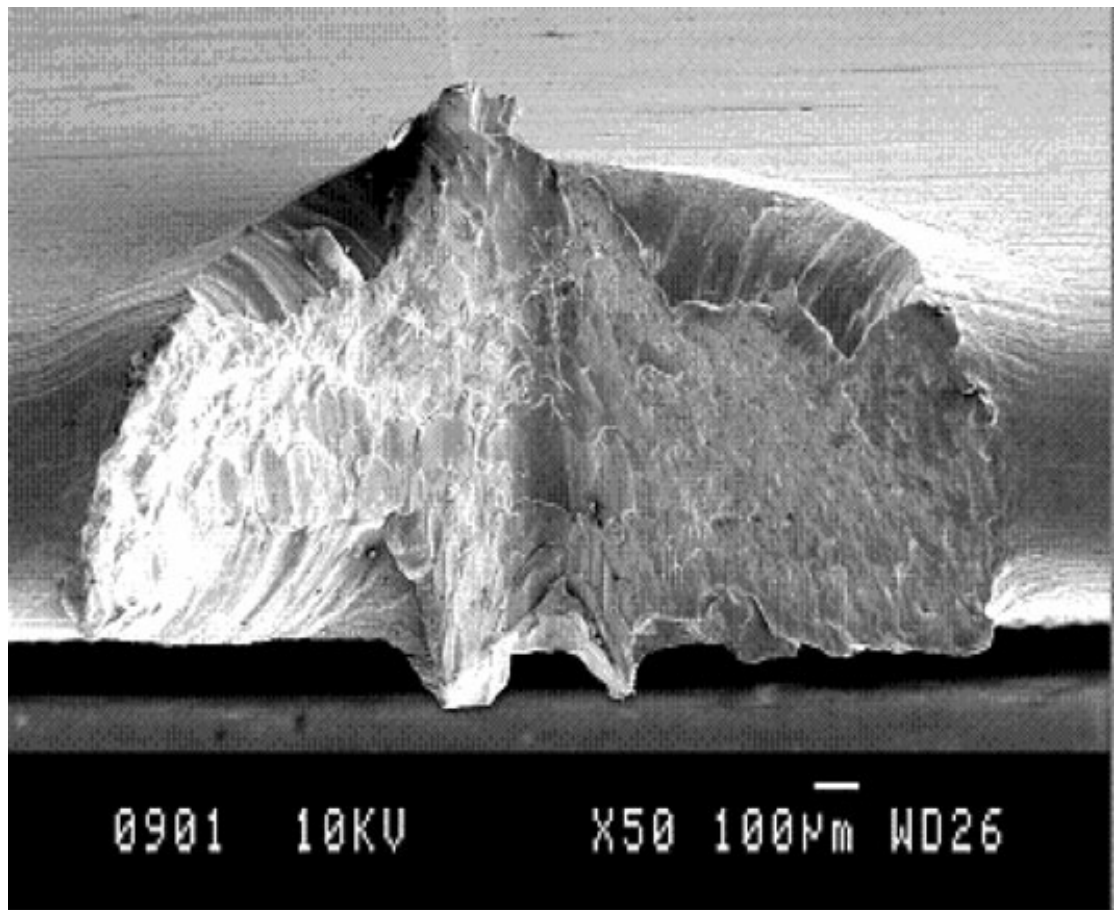

(a)

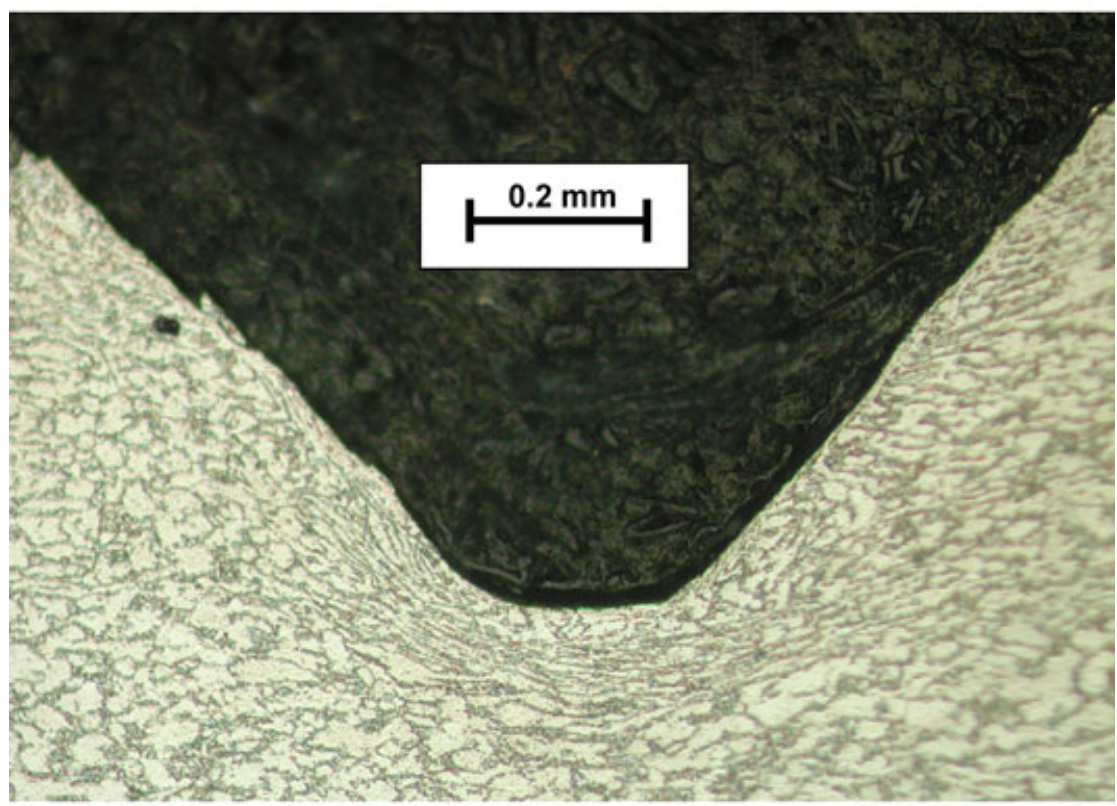

(b)

Fig. 2 (a) FOD indent produced by leading edge impact (nose-on) of a $3 \mathrm{~mm}$ cubic projectile at $200 \mathrm{~m} / \mathrm{s}$. (b) A section parallel to the long axis of the specimen through the FOD indent; material polished and etched to reveal micro-structural damage in the vicinity of FOD.

where $\dot{\varepsilon}$ is the strain rate, $\sigma_{Y}(\dot{\varepsilon})$ is the strain-rate sensitive yield stress, $\sigma_{y}^{0}$ is the yield stress at $\dot{\varepsilon}=0$, and $\dot{\varepsilon}_{r}$ is a reference strain rate. Parameter $\dot{\varepsilon}_{r}$ was taken as $2 \times 10^{-4} \mathrm{~s}^{-1}$ while $n$ was taken as $3 .{ }^{9}$ Enhanced hourglass control was assigned to the part of the aerofoil model close to the location where the impact occurred. Convergence stud- ies were carried out where four different meshes (finest, fine, medium and coarse) were examined and the results differed less than $5 \%$ between the fine and finest meshes, hence the former was selected. The final model consists of 75466 nodes and 65408 elements. Only material deformation was modelled in the study, while material failure 


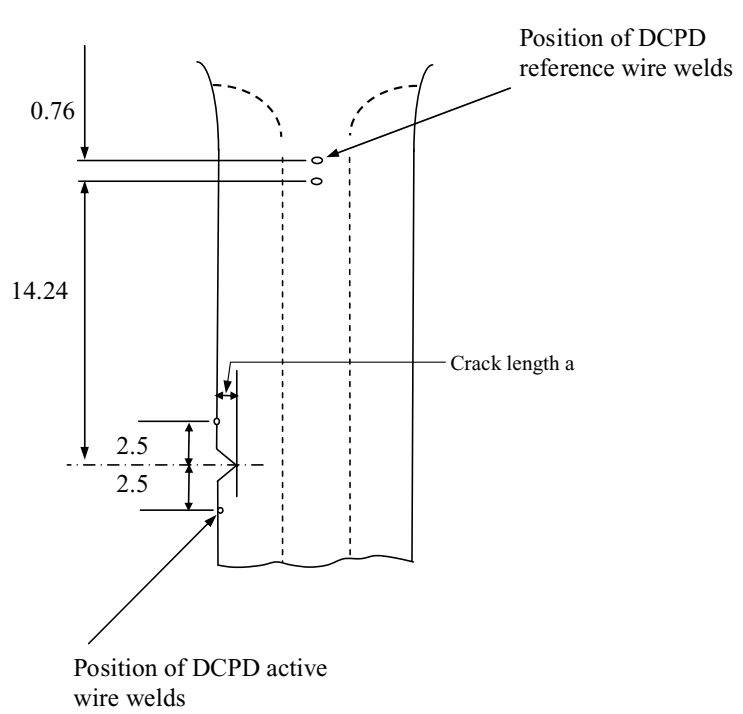

(a)

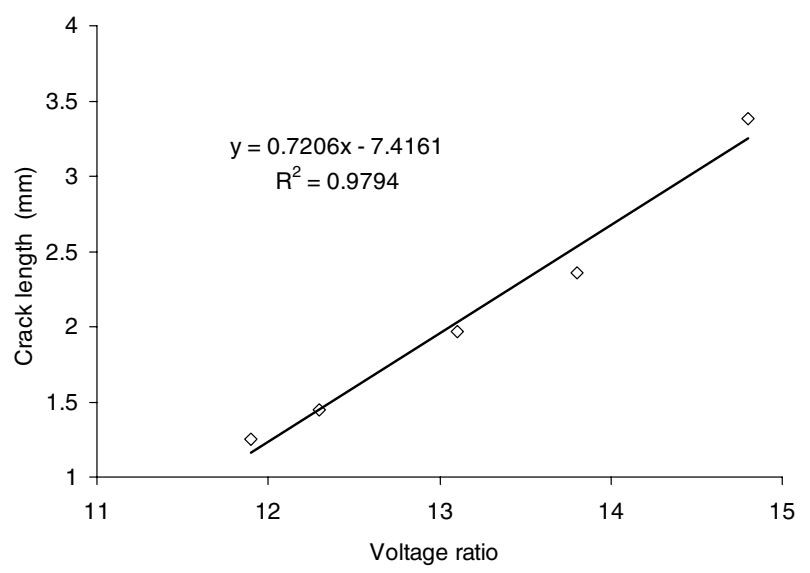

(b)

Fig. 3 (a) Positions of the active and reference DCPD leads used for monitoring crack growth. Crack length a (with indent depth included) is also indicated. (b) Relationship between the voltage ratio and the crack length; data obtained by measurement of crack lengths post experiments.

during the impact was ignored. Although the latter allows elements to be removed from the mesh after a critical plastic strain is exceeded, the elements consistently failed and led to unrealistic results, hence the complex failure mechanisms seen in the formation of impact notches, such as tearing or shear bands, were not reproduced in the current analysis.

\section{Analysis of residual stresses}

To characterise the stabilised FOD indent geometry and the associated residual stresses, the data from the time-dependent explicit analysis of the dynamic impact

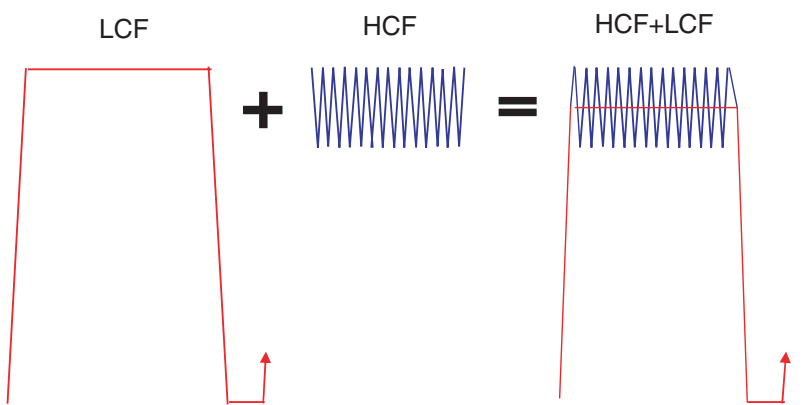

Fig. 4 A schematic representation of a combined HCF + LCF loading block.

Table 1 A summary of specimen types and loading conditions

\begin{tabular}{|c|c|c|c|c|}
\hline $\begin{array}{l}\text { Specimen } \\
\text { condition }\end{array}$ & $\begin{array}{l}\text { Number } \\
\text { of tests }\end{array}$ & $\begin{array}{l}\text { Type of } \\
\text { loading }\end{array}$ & $\begin{array}{l}\text { Load ratio } \\
\mathrm{R}\end{array}$ & $\begin{array}{l}\text { Cycle ratio } \\
\text { HCF:LCF }\end{array}$ \\
\hline As-FOD & 2 & LCF-only & 0.1 & n.a. \\
\hline As-FOD & 2 & HCF-only & 0.7 & n.a. \\
\hline As-FOD & 2 & $\mathrm{LCF}+\mathrm{HCF}$ & $\begin{array}{l}0.1 \text { (LCF) } \\
0.7 \text { (HCF) }\end{array}$ & 1000:1 \\
\hline Stress relieved & 1 & LCF-only & 0.1 & n.a. \\
\hline Stress relieved & 1 & $\mathrm{LCF}+\mathrm{HCF}$ & $\begin{array}{l}0.1 \text { (LCF) } \\
0.7 \text { (HCF) }\end{array}$ & 1000:1 \\
\hline
\end{tabular}

must be reprocessed through a time-independent implicit analysis. The latter analysis, achieved by using ABAQUS/Standard, ${ }^{25}$ removed both dynamic forces (including inertia and damping) and boundary interaction forces and resulted in a residual stress state associated with static equilibrium. The longitudinal (external loading direction) residual stress distribution $\sigma_{\mathrm{r}}$ on the mid-plane of the specimen was obtained from the above procedure, as shown in Fig. 8. Clearly, higher tensile stresses are obtained on the surface and subsurface of the specimen near the vicinity of the FOD indent, and they are balanced by the compressive stresses further inside of the specimen. Some locations on the specimen surface proved to be unfavourable for the attachment of DCPD leads, as described earlier. The depth of the indent was found to be $0.7 \mathrm{~mm}$, comparable to $0.75 \pm 0.12 \mathrm{~mm}$, as measured post-FOD impacts.

\section{Modified stress intensity factor solution}

The stress intensity factor for FOD-induced crack growth was determined by considering the longitudinal residual stresses in a plane stress model of the mid-section of the aerofoil specimen. Both geometric stress concentration due to FOD and residual stresses were considered. Due to symmetry, only half of the specimen was modelled. The six-node modified plane stress element CPS6M and 


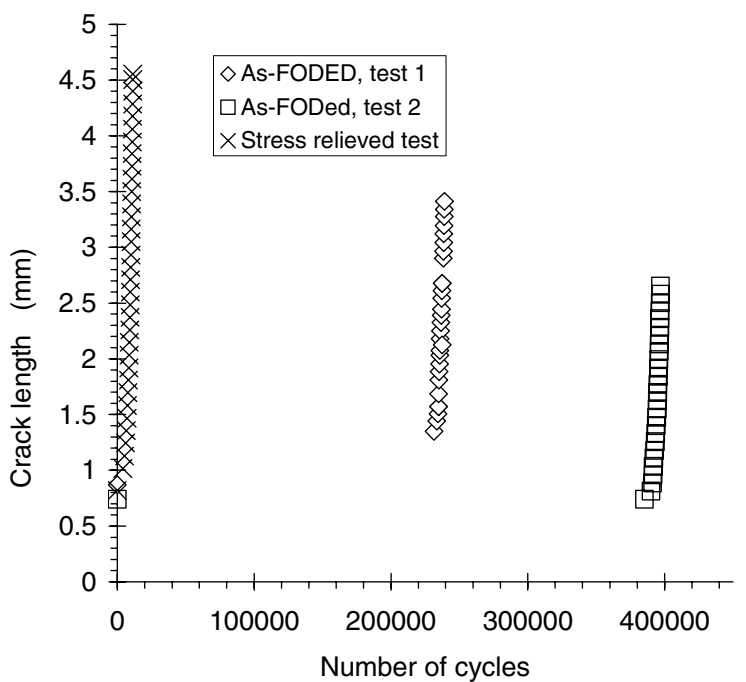

(a)

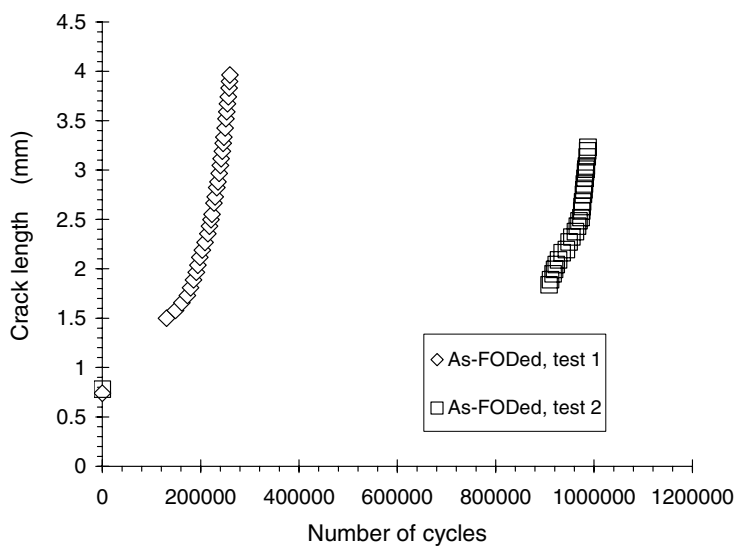

(b)

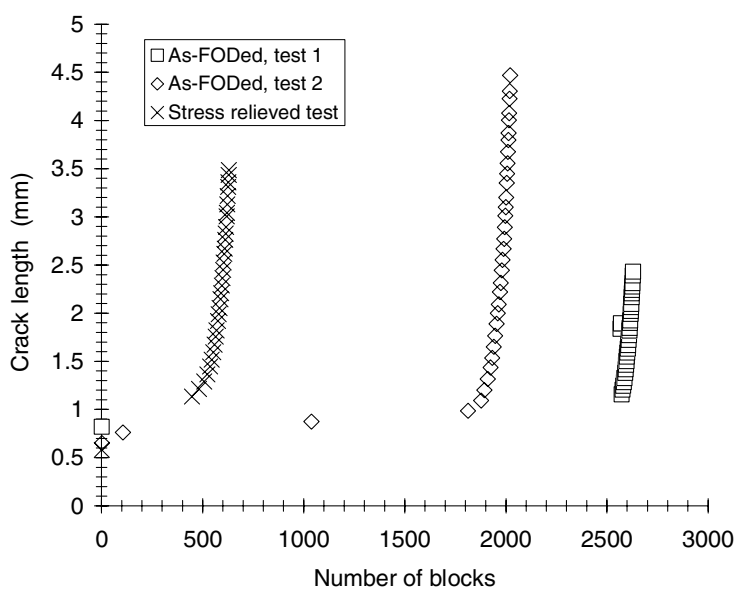

(c)

Fig. 5 Crack length versus number of cycles for (a) LCF cycles, $\mathrm{R}=0.1$. Experimental results from two as-FoDed specimens and one FOD + stress relieved specimen; (b) HCF cycles, $\mathrm{R}=0.7$.

Experimental results for two as-FODed specimens; (c) LCF + HCF block loading, $\mathrm{R}_{\mathrm{HCF}}=0.7 ; \mathrm{n}=1000: 1$. Experimental results from two as-FoDed specimens and one FOD + stress relieved specimen.

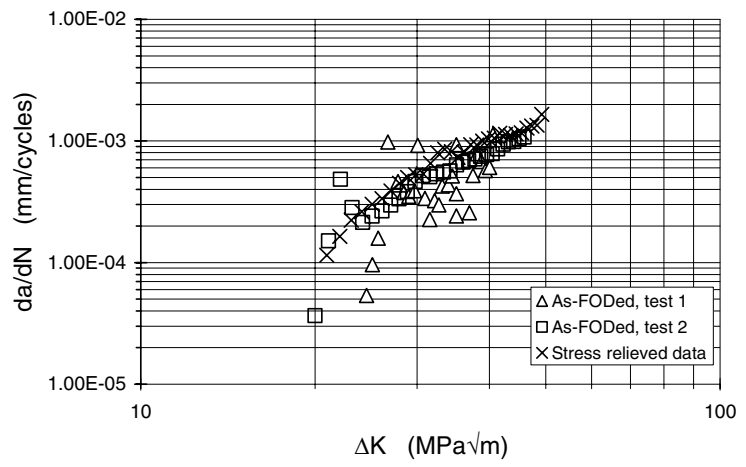

(a)

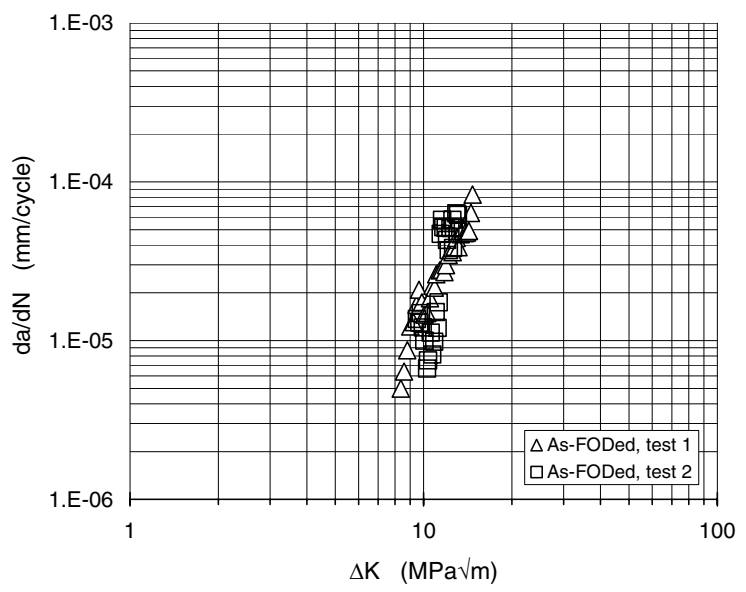

(b)

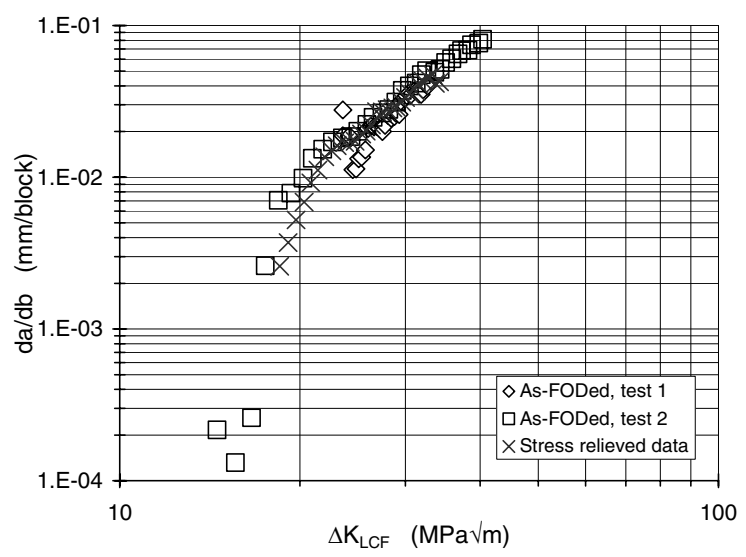

(c)

Fig. 6 Fatigue crack growth versus stress intensity factor range estimated using single edge crack solution for loading conditions: (a) $\mathrm{LCF}, \mathrm{R}=0.1$; (b) HCF, $\mathrm{R}=0.7$; (c) $\mathrm{HCF}+\mathrm{LCF}, \mathrm{R}_{\mathrm{HCF}}=0.7$; $\mathrm{n}=1000: 1$.

the eight-node biquadratic, reduced integration element $\mathrm{CPS} 8 \mathrm{R}$ were used. The latter was employed near the crack tip area with refined local meshing to capture the large stress gradient. The model was subjected to a remote longitudinal uniform stress of $361 \mathrm{MPa}$, as in the experiments. 


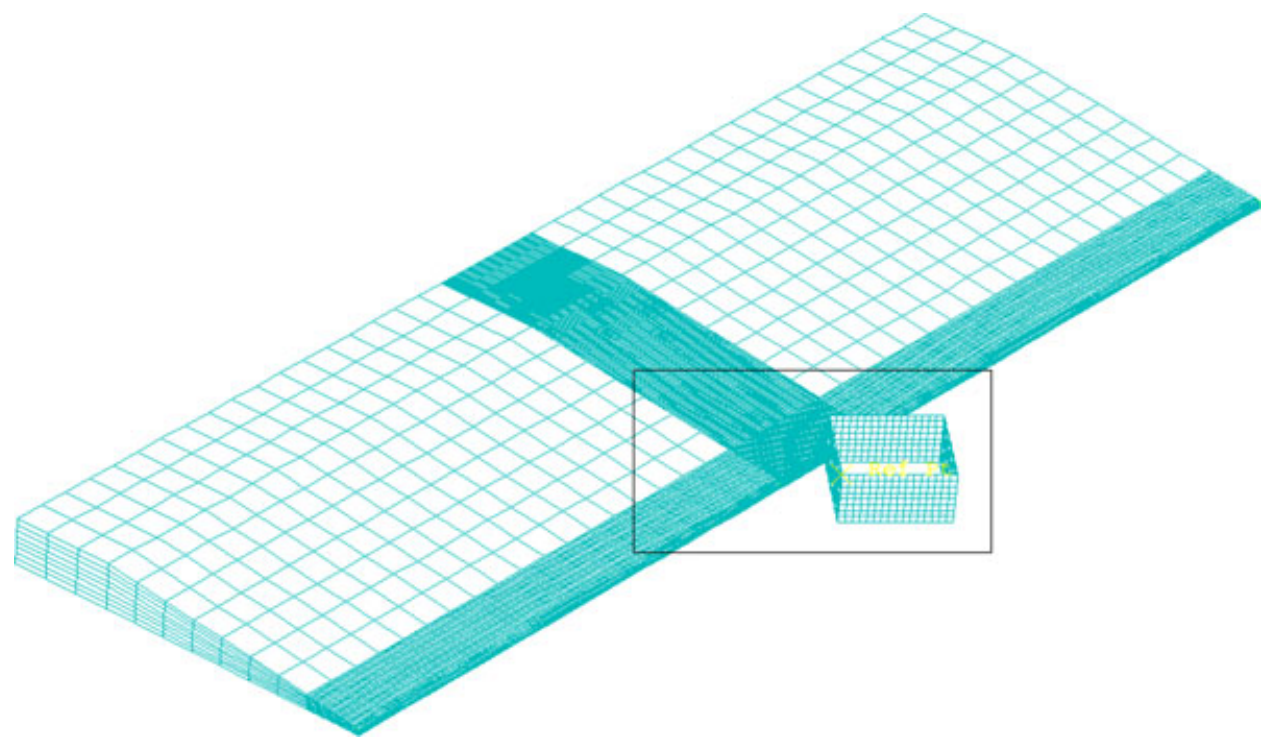

Fig. 7 The finite element model of the aerofoil specimen with a cube impacting onto the leading edge of the specimen.

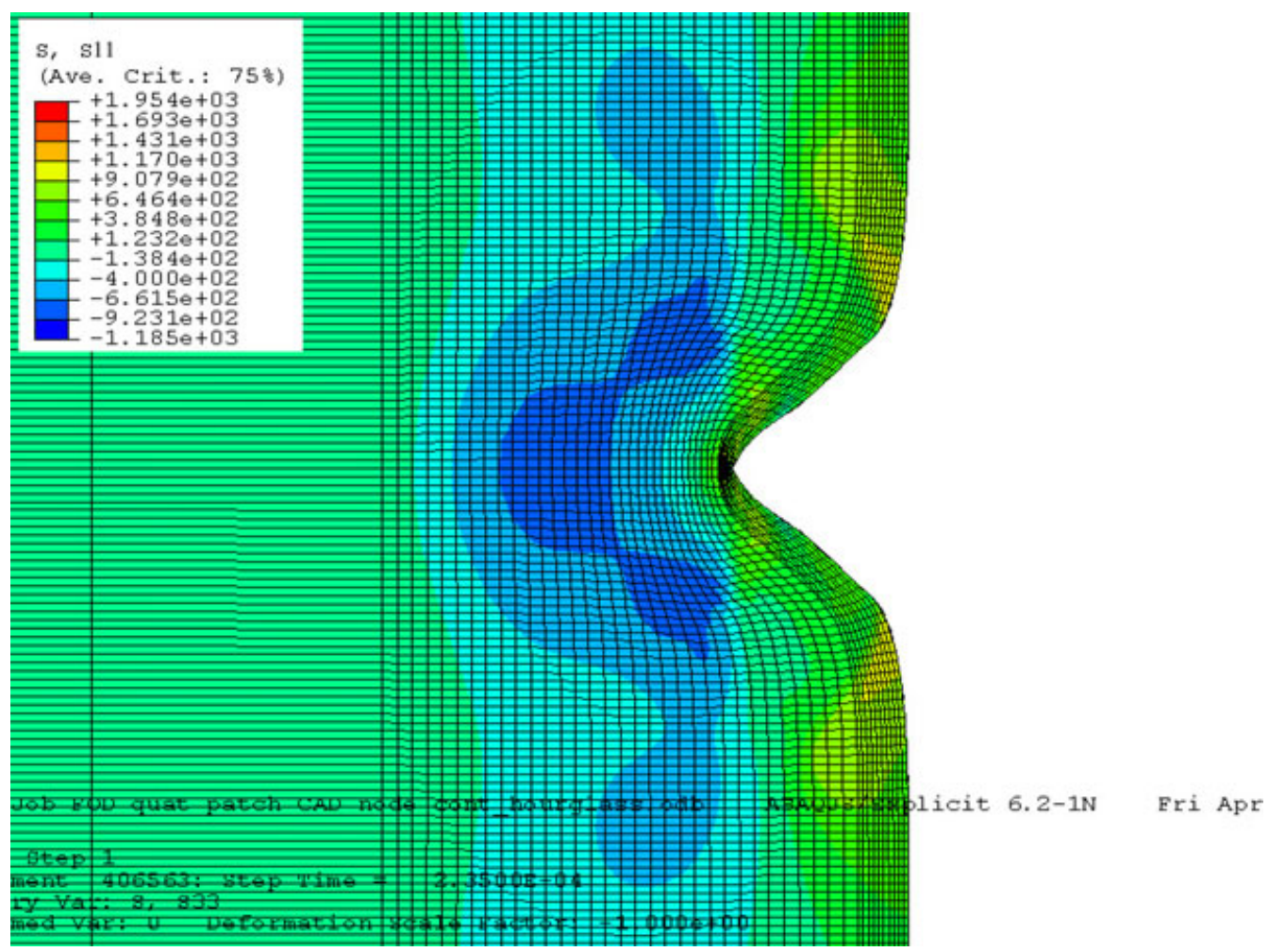

Fig. 8 Longitudinal stress distributions on the mid-plane of the aerofoil specimen due to impact of a cubic projectile at $200 \mathrm{~m} / \mathrm{s}$. The unit of the stress is $\mathrm{MPa}$.

To consider the residual stresses due to FOD in the calculation of crack driving force, several methods may be used. A modified J-integral was developed ${ }^{26}$ in which residual stresses were treated as an initial strain problem. Cook et al..$^{27}$ used a superposition method to account for the effect of residual stresses from shot peening in the analysis of crack growth, using a ABAQUS/DLOAD subroutine. The residual stress distribution was introduced as a subsurface nodal temperature distribution. This latter method was adopted for the current analysis. A unidirectional stress distribution was introduced perpendicular to the perceived crack growth path, representative 


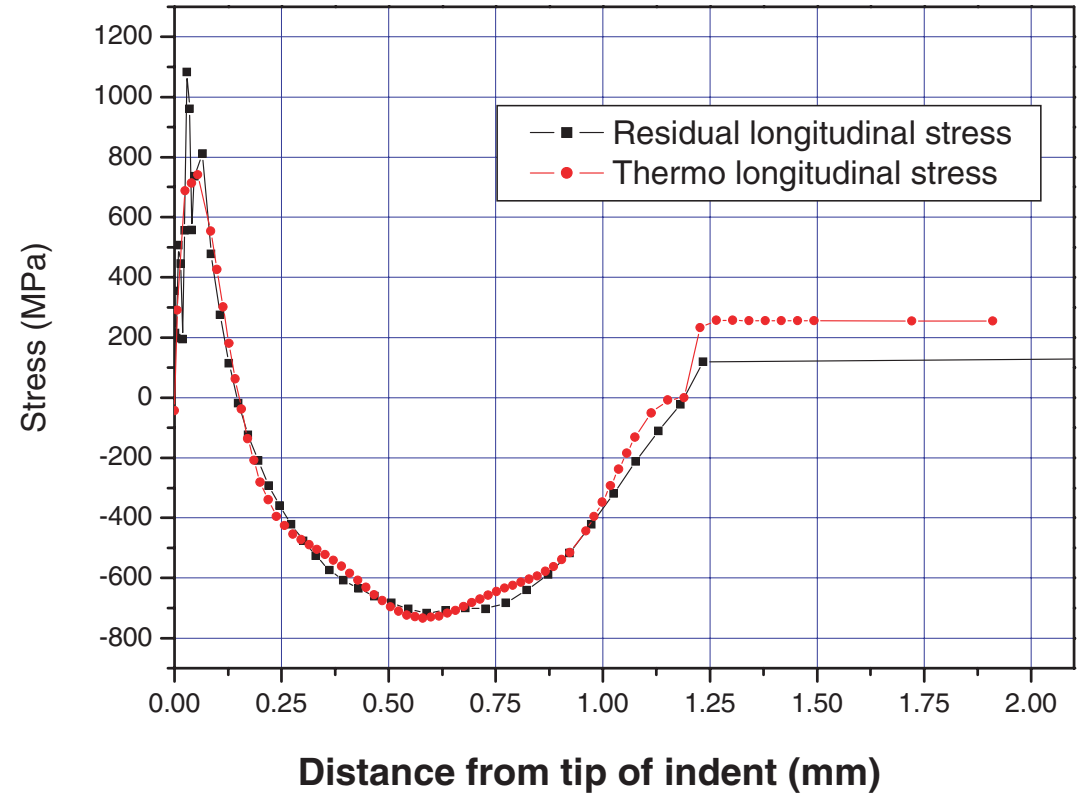

Fig. 9 Residual longitudinal stress distributions along the crack path, comparison of the FE result (Fig. 8) and the simulated thermal stresses from a nodal temperature distribution field. of the most significant residual stress distribution due to FOD, as obtained earlier. The unidirectional residual stress distribution was introduced as a nodal temperature distribution field, using ABAQUS subroutine UTEMP. The thermal expansion properties associated with material modelling were defined using *EXPANSION, TYPE $=$ ORTHO and the coefficient of expansion was specified as equal to the reciprocal of the Young's modulus. The thermo stress resulting from the temperature distribution is shown in Fig. 9, together with the longitudinal residual stress distribution from the $\mathrm{FE}$ analysis presented earlier (Fig. 8). Apart from the locations very close to the indent $(<0.1 \mathrm{~mm})$, where the stresses were underestimated; and away from the indent $(>1.25 \mathrm{~mm})$, where they were slightly overestimated, the longitudinal residual stresses were reproduced satisfactorily by the thermo stresses as a result of the assumed temperature distribution.

The stress intensity factor in a complex stress field including both the remote applied uniform stress field and the simplified residual stress field as introduced above was estimated using ABAQUS. The modified geometry factor for the combined stress intensity factor may be expressed by a polynomial-fitted curve:

$$
\begin{aligned}
& \frac{K_{1}}{\sigma \sqrt{\pi a}}=\mathrm{A}+\mathrm{B}_{1}\left(\frac{\mathrm{a}}{\mathrm{W}}\right)+\mathrm{B}_{2}\left(\frac{\mathrm{a}}{\mathrm{W}}\right)^{2}+\mathrm{B}_{3}\left(\frac{\mathrm{a}}{\mathrm{W}}\right)^{3} \\
& \quad+\mathrm{B}_{4}\left(\frac{\mathrm{a}}{\mathrm{W}}\right)^{4}+\mathrm{B}_{5}\left(\frac{\mathrm{a}}{\mathrm{W}}\right)^{5}+\mathrm{B}_{6}\left(\frac{\mathrm{a}}{\mathrm{W}}\right)^{6}+\mathrm{B}_{7}\left(\frac{\mathrm{a}}{\mathrm{W}}\right)^{7} \\
& \quad+\mathrm{B}_{8}\left(\frac{\mathrm{a}}{\mathrm{W}}\right)^{8}+\mathrm{B}_{9}\left(\frac{\mathrm{a}}{\mathrm{W}}\right),{ }^{9}
\end{aligned}
$$

where $\sigma$ is the remote stress, $a$ is the crack length, $W$ is the width of the aerofoil specimen. The polynomial parameters $A$ and $B_{i}(i=1-9)$ are presented in Table 2, with the units of stress and length in $\mathrm{MPa}$ and $\mathrm{m}$, respectively. A collection of stress intensity factors are presented in Fig. 10, including solutions for the aerofoil specimen without residual stresses (marked as annealed specimen); with the residual stresses considered (Eq. (2)) and rectangular cross-section plate specimens with $\mathrm{H} / \mathrm{W}=1$ and $\rightarrow \infty .{ }^{24}$ It is immediately clear that the stress intensity factor considering residual stress distribution differs considerably from that without residual stresses or those of plate specimens, particularly for $0.05<\mathrm{a} / \mathrm{W}$ $<0.25$ where significantly reduced stress intensity occurs due to the presence of the compressive residual stresses.

\section{DISCUSSION}

The modified stress intensity factors with residual stresses considered were used to correlate the measured crack growth rates under LCF, HCF and combined LCF and HCF loading conditions, and the results are presented in Fig. 11. A significant change from the results presented in Fig. 6, common to all loading conditions, is the crack growth at considerably reduced values of $\Delta \mathrm{K}$ for as-FODed specimens, due to the presence of the compressive residual stresses. When the value of $\Delta \mathrm{K}$ is above $25 \mathrm{MPa} \sqrt{ } \mathrm{m}$, the crack growth rates from the as-FODed and stress-relieved specimens become similar as the cracks grow away from the influence of the FOD. At low $\Delta \mathrm{K}$ 


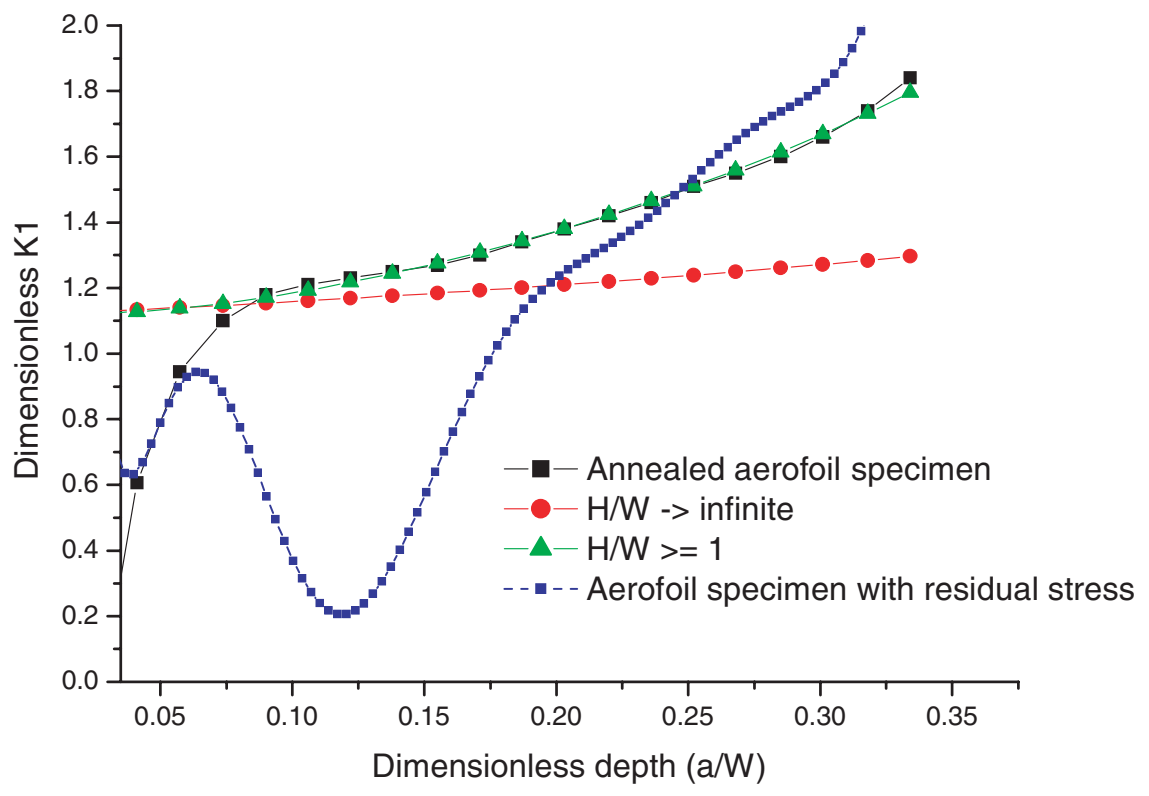

Fig. 10 Comparison of stress intensity factors including: Finite element solutions for a crack in an aerofoil specimen with and without (annealed) residual stresses; edge crack solutions $(\mathrm{H} / \mathrm{W} \geq 1$ and $\mathrm{H} / \mathrm{W} \rightarrow \infty)$.

Table 2 The polynomial parameters used in the modified stress intensity factor corrected for residual stress $\sigma_{\mathrm{r}}$

\begin{tabular}{llllll}
\hline Parameter & $\mathrm{A}$ & $\mathrm{B}_{1}$ & $\mathrm{~B}_{2}$ & $\mathrm{~B}_{3}$ & $\mathrm{~B}_{4}$ \\
\hline Value & 16.37 & -1373 & 47410 & -847100 & $8.760 \mathrm{E} 6$ \\
\hline Parameter & $\mathrm{B}_{5}$ & $\mathrm{~B}_{6}$ & $\mathrm{~B}_{7}$ & $\mathrm{~B}_{8}$ & $\mathrm{~B}_{9}$ \\
\hline Value & $-5.538 \mathrm{E} 7$ & $2.175 \mathrm{E} 8$ & $-5.181 \mathrm{E} 8$ & $6.860 \mathrm{E} 8$ & $-3.873 \mathrm{E} 8$ \\
\hline
\end{tabular}

values, variation in crack growth rates is evident, reflecting the discontinuous nature of the early crack growth due to residual stresses close to the root of the FOD indent.

For LCF-only cycles, a comparison of Figs. 6a and 11a reveals much accelerated early crack growth rates in FODed specimens when residual stresses are considered. For a $\Delta \mathrm{K}$ value about $4.5 \mathrm{MPa} \sqrt{ } \mathrm{m}$, crack growth rates are in the region of $5 \times 10^{-5}$ to $3 \times 10^{-4}$, as opposed to the same growth rates for a $\Delta \mathrm{K}$ value of about $20 \mathrm{MPa} \sqrt{ } \mathrm{m}$ when the residual stresses are ignored. Distinctly different correlations between the crack growth rates and $\Delta K$ for FODed specimens and stress-relieved specimen are observed. For HCF-only cycles, early crack growth appears to start at a $\Delta \mathrm{K}$ value less than $2 \mathrm{MPa} \sqrt{ } \mathrm{m}$ (Fig. 11b), suggesting again small crack growth behaviour. A similar picture emerged for the case under combined LCF + HCF loading blocks (Fig. 11c), again, around $\Delta \mathrm{K} \approx$ $4 \mathrm{MPa} \sqrt{ } \mathrm{m}$, early crack growth is observed, with signifi- cant scatters in the data for $\Delta \mathrm{K}<20 \mathrm{MPa} \sqrt{ } \mathrm{m}$; while above $25 \mathrm{MPa} \sqrt{ } \mathrm{m}$, crack growth rates of FODed and stress relieved specimens become similar, due to the diminishing influence of the residual stresses.

It is interesting to note that the small crack growth behaviour during the early phases of crack growth post-FOD impact is common to all FODed specimens, irrespective of the subsequent loading conditions. This characteristic is revealed only after the predominant residual stress component, that is the longitudinal residual stress, is considered in the calculation of the stress intensity factor. This illustrates the importance of considering residual stresses towards a more accurate assessment of the stress intensity factor as the crack driving force. Conventional analysis that considers only the geometry effect of a notch is clearly inadequate, as it will significantly underestimate fatigue crack growth at low stress intensity factor ranges.

Fatigue crack growth rates are a function of both the stress amplitude and mean stress; hence the influence of residual stresses is significant on fatigue crack growth. ${ }^{28}$ Prediction of fatigue crack growth rates in the presence of residual stresses is of broad interest as residual stresses can arise from many sources, such as during manufacturing processes (welding, machining, casting and forging), surface treatment (shot peening, laser shot peening, low plasticity burnishing) as well as in-service loading conditions such as FOD. Modelling of crack growth in a residual stress field has been approached by using the weight function method, ${ }^{29,30}$ modified J-integral ${ }^{26}$ or crack 


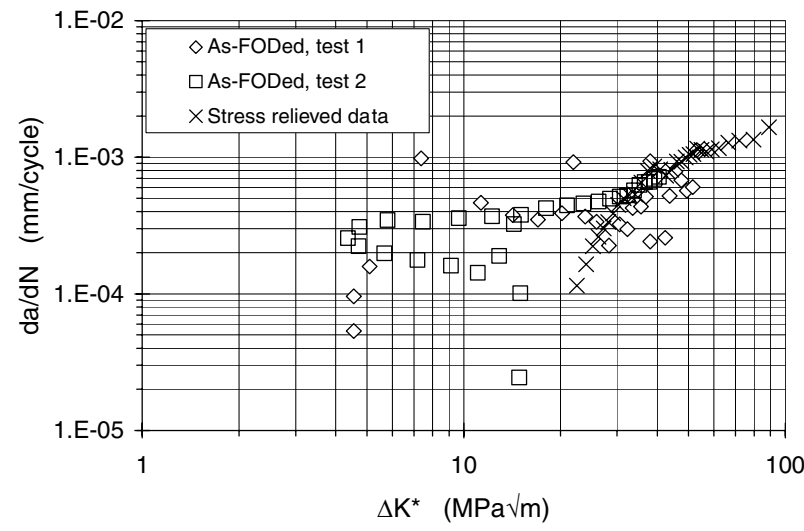

(a)

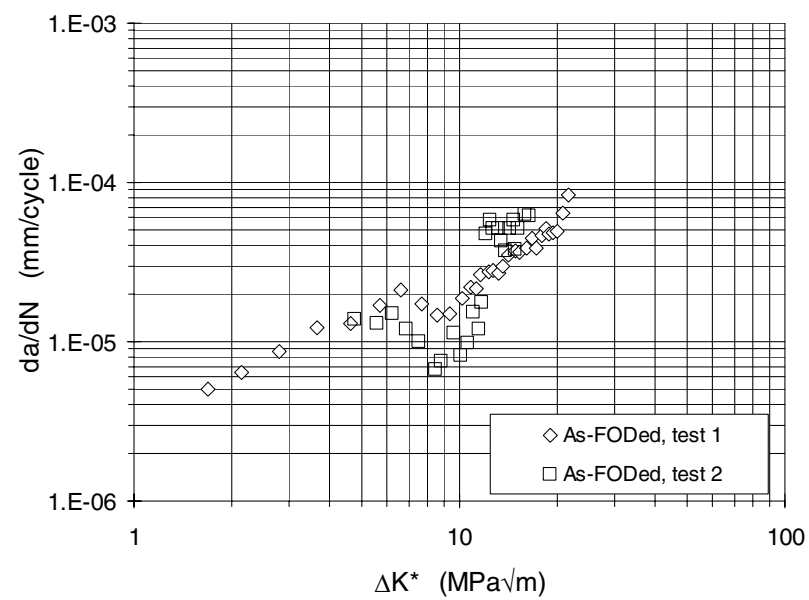

(b)

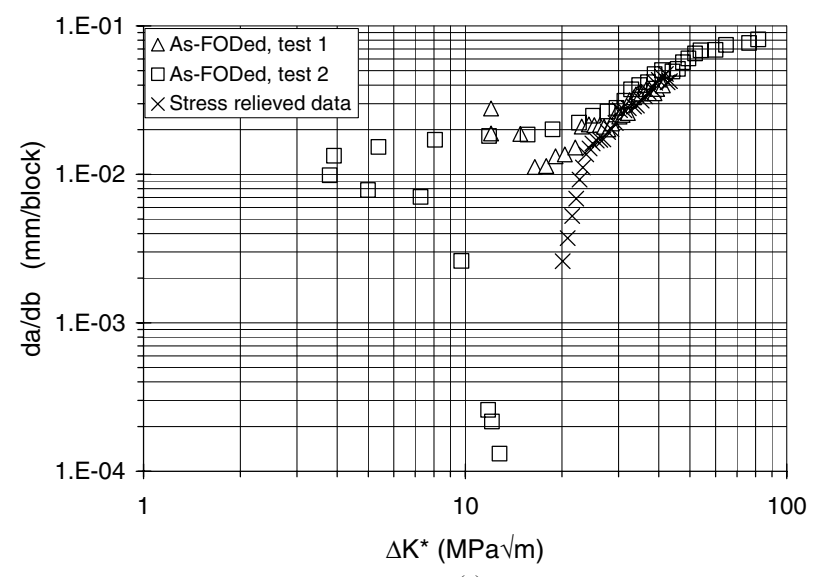

(c)

Fig. 11 Fatigue crack growth rates correlated with the modified stress intensity factor range $\Delta \mathrm{K}^{*}$ corrected for residual stresses for loading conditions: (a) LCF; (b) HCF; (c) LCF $+\mathrm{HCF}\left(\Delta \mathrm{K}_{\mathrm{LCF}}^{*}\right)$.

compliance method, ${ }^{31,32}$ the latter allows stress intensity factor to be determined without prior knowledge of the residual stress field. Complete residual stress fields were available only very recently, ${ }^{33}$ where the residual stresses measured by neutron diffraction and an equilibriumbased least square algorithm was used to reconstruct the full residual stress field. Admittedly, the present analysis considered only a unidirectional residual stress distribution along the perceived crack path. The influence of full field 3D residual stresses on the crack tip stress fields is yet to be assessed.

The residual stress redistribution and the modified stress intensity factor due to the residual stress field may be calculated during the crack extension. Correlation of the residual stress intensity with crack growth rate seems to suggest that minimum crack growth rates are obtained for negative true load ratios and there is a large scatter in the crack growth rates in the presence of a residual stress field. Admittedly, the residual stresses may be overestimated in the current work, as no stress relaxation or redistribution was considered in the analysis. The initial steady-state residual stresses associated with FOD may not persist because of the potential relaxation or redistribution during subsequent fatigue loading and/or crack extension. The magnitude and rate of relaxation have been found to be dependent on the initial residual stress, applied loads and FOD-induced stress concentration. ${ }^{6,33}$ The stress relaxation is typically associated with the reordering of dislocations and the occurrence of cyclic softening, that is reduction in the flow stress during cyclic loading. In addition, upon the formation of a fatigue crack, the relaxation can further increase due to the stress-concentration effect and plasticity associated with the crack. ${ }^{6}$ More accurate residual stress analysis that considers full field stresses and stress relaxation is required if the crack driving force is to be determined accurately.

\section{CONCLUSIONS}

Fatigue crack growth from FOD under LCF, HCF and combined LCF and HCF loading conditions has been investigated in aerofoil Ti6Al4V alloy specimens. Residual stresses due to FOD were simulated using a dynamic finite element analysis, and the longitudinal stress component was introduced as a temperature distribution in an aerofoil section. A modified stress intensity factor solution was derived from the finite element analysis and used to correlate the fatigue crack growth rates. There are significant differences in the early crack growth behaviour between specimens retaining residual stresses and those where the residual stresses were removed by annealing; also between the correlations using the nominal stress intensity factor and a modified stress intensity factor considering the residual stresses. Small crack growth behaviour in FODed specimens was revealed only after the residual stresses were taken into account in the calculation of stress intensity factor, common to LCF, HCF and combined LCF + HCF loading conditions. 


\section{Acknowledgements}

Funding from EPSRC/MOD (Grant GR/R79258/01), the supply of specimens by Rolls-Royce plc and the imparting of FOD by QinetiQ are gratefully acknowledged. The authors would like to thank Professor Mike Winstone of dstl; Drs. David Rugg, John Schofield, Martin Rawson of Rolls-Royce plc; Mr. P Tranter of QinetiQ for many helpful discussions during the course of the work.

\section{REFERENCES}

1 Bachtel, B. (1998) Foreign object debris and damage prevention. Aeromagazine 1, Article S.

2 Nicholas, T. (1999) Critical issues in high cycle fatigue. Int. 7. Fatigue, 21, S221-S231.

3 Ritchie, R. O., Davidson, D. L., Boyce, B. L., Campbell, J. P., Roder, O. (1999) High-cycle fatigue of Ti-6Al-4V. Fatigue Fract. Eng. Mater. Struct. 22, 621-631.

4 Peters, J. O. and Ritchie, R. O. (2000) Influence of foreign-object damage on crack initiation and early crack growth during high-cycle fatigue of Ti-6Al-4V. Eng. Frac. Mech. 67, 193-207.

5 Peters, J. O., Boyce, B. L., Chen, X., MaNaney, J. M., Hutchinson, J. W. and Ritchie, R. O. (2002) On the application of the Kitagawa-Takahashi diagram to foreign-object damage and high cycle fatigue. Eng. Fract. Mech. 69, 1425-1446.

6 Boyce, B. L., Chen, X., Peters, J. O., Hutchinson, J. W. and Ritchie, R. O. (2003) Mechanical relaxation of localised residual stress associated with foreign object damage. Mater. Sci. Engng. A349, 48-58.

7 Boyce, B. L., Chen, X., Hutchinson, J. W. and Ritchie, R. O. (2001) The residual stress state due to a spherical hard-body impact. Eng. Fract. Mech. 68, 129-147.

8 Chen, X. and Hutchinson, J. W. (2001) Foreign object damage and fatigue crack threshold: cracking outside shallow indents. Int. F. Fracture 107, 31-51.

9 Chen, X. and Hutchinson, J. W. (2002) Particle impact on metal substrates with application to foreign object damage to aircraft engines. 7. Mech. Phy. Solids 50, 2669-2690.

10 Thompson, S. R., Ruschau, J. J. and Nicholas, T. (2001) Influence of residual stresses on high cycle fatigue strength of Ti-6Al-4V subjected to foreign object damage. Int. F. Fatigue 23, S405-S412.

11 Mall, S., Hamrick, J. L. and Nicholas, T. (2002) High cycle fatigue life of Ti-6Al-4V with simulated foreign object damage. Mech. Mater. 33, 679-682.

12 Ruschau, J. J., Thompson, S. R. and Nicholas, T. (2003) High cycle fatigue limit stresses for airfoils subjected to foreign object damage. Int. 7. Fatigue 25, 955-962.

13 Bache, M. R., Evans, W. J. and Voice, W. (2002) The resistance to impact damage and subsequent fatigue response of two titanium alloys. Mater. Sci. Engng. A333, 287-294.

14 Bache, M. R., Bradshaw, C. and Voice, W. (2003) Characterisation of foreign object damage and fatigue strength in titanium based aerofoil alloys. Mater. Sci. Engng. A334, 199-206.

15 Nowell, D., Duo, P. and Stewart, I. F. (2003) Prediction of fatigue performance in gas turbine blades after foreign object damage. Int. 7. Fatigue 25, 963-969.
16 Oaklet, S. Y. and Nowell, D. (2007) Prediction of the combined high- and low-cycle fatigue performance of gas turbine blades after foreign object damage. Int. F. Fatigue 29, 6980.

17 Duo, P., Liu, J., Dini, D., Golshan, M. and Korsunsky, A. M. (2007) Evaluation and analysis of residual stresses due to foreign object damage. Mech. Mater. 39, 199-211.

18 Ding, J., Hall, R. F., Byrne, J. and Tong, J. (2007) Fatigue crack growth from foreign object damage under combined high and low cycle loading conditions. Part I: Experimental studies. Int. 7. Fatigue 29, 1339-1349.

19 Ding, J., Hall, R. F., Byrne, J. and Tong, J. (2007) Fatigue crack growth from foreign object damage under combined high and low cycle loading conditions. Part II: A two-parameter predictive approach. Int. F. Fatigue. 29, 1350-1358.

20 El. Haddad, M. H., Topper, T. H. and Smith, K. N. (1979) Prediction of non propagating cracks. Eng. Fract. Mech. 11, 573-584.

21 Hawkyard, M., Powell, B. E., Stephenson, J. M. and McElhone, M. (1999) Fatigue crack growth from simulated flight cycles involving superimposed vibrations. Int. F. Fatigue 23, S59S68.

22 Evans W. J., Bache M. R., McElhone M. and Grabowski L. (1997) Environmental interactions with fatigue crack growth in alpha/beta titanium alloys. Int. F. Fatigue 19, 177-182.

23 Powell, B. E., Duggan, T. V. and Jeal, R. H. (1982) The influence of minor cycles on low cycle fatigue crack propagation. Int. 7. Fatigue 4, 4-14.

24 Pickard, A. C. (1986) The application of 3-dimensional finite element methods to fracture mechanics and fatigue life predictions. EMAS Warrington, UK.

25 ABAQUS (2005) Analysis User's Manual, Hibbitt, Karlsson \& Sorensen, Inc., RI, USA.

26 Lei, Y., O'Dowd, N. P. and Webster, G. A. (2000) Fracture mechanics analysis of a crack in a residual stress field. Int. $\mathcal{F}$. Fract. 106, 195-216.

27 Cook, G., Timbrell, C. M. and Wiehahn, M. (2002) Using ABAQUS to analysis fatigue crack growth under the combined influence of residual stress and cyclic external load. UK ABAQUS User Group Conference Warrington, UK.

28 McClung, R. C. (2007) A literature survey on the stability and significance of residual stresses during fatigue. Fatigue Fract. Engng. Mater. Struct. 30, 173-205.

29 Parker, P. (1982) Stress intensity factors, crack profiles and fatigue crack growth rates in residual stress fields. ASTM STP 776, ASTM, 13-31.

30 Daniewicz, S. R., Collins, J. A. and Houser, D. R. (1994) An elastic-plastic analytical model for prediction fatigue crack growth in arbitrary edge-cracked two-dimensional geometries with residual stress. Int. F. Fatigue 16, 123-133.

31 Schindler, H. -J., Cheng, W. and Finnie, I. (1997) Experimental determination of stress intensity factors due to residual stresses. Exp. Mech. 37, 272-277.

32 Prime, M. B. (1999) Measuring residual stress and the resulting stress intensity factor in compact tension specimens. Fatigue Fract. Engng. Mater. Struct. 22, 195-204.

33 Sutton, M. A., Reynolds, A. P., Ge, Y. Z. and Deng, X. (2006) Limited weld residual stress measurements in fatigue crack propagation: Part II, FEM-based fatigue crack propagation with complete residual stress fields. Fatigue Fract. Eng. Mater. Struct., 29, 537-545. 